Int. J. Electrochem. Sci., 15 (2020) 947 - 958

\title{
Graphene quantum dots/ionic liquid-Modified Carbon Paste Electrode-Based Sensor for Simultaneous voltammetric determination of norepinephrine and acetylcholine
}

\author{
Peyman Mohammadzadeh Jahani ${ }^{1}$, Maedeh Jafari ${ }^{2}$, Vinod Kumar Gupta ${ }^{3, *}$, Shilpi Agarwal \\ ${ }^{1}$ School of Medicine, Bam University of Medical Sciences, Bam, Iran \\ ${ }^{2}$ Department of Pediatrics, School of Medicine, Kerman University of Medical Sciences, Kerman, Iran \\ ${ }^{3}$ Center of Excellence for Advanced materials Research King Abdulaziz University, Jeddah, Saudi \\ Arabia \\ *E-mail: vinodfcy@ gmail.com
}

doi: $10.20964 / 2020.01 .45$

Received: 30 September 2019/ Accepted: 4 November 2019 / Published: 30 November 2019

In this work, a highly effective voltammetric sensor fabricated for simultaneous analysis of norepinephrine and acetylcholine. The sensor was fabricated by the modification of carbon paste electrode with graphene quantum dots/ionic liquid (GQDs/IL/CPE). The electrochemical behavior of epinephrine on the modified electrode was studied using cyclic voltammetry $(\mathrm{CV})$, differential pulse voltammetry (DPV) and chronoamperometry (CHA). The results indicate that the electrochemical responses are improved significantly with the use of the modified electrode. The calibration curve obtained by DPV, under the optimized conditions, showed linear range of $0.2-400.0 \mu \mathrm{M}$ for norepinephrine (limit of detection $0.06 \mu \mathrm{M}$ ). The sensor was successfully used to detect the analytes in real samples.

Keywords: Voltammetric sensor, Norepinephrine, Acetylcholine, Graphene quantum dots, Ionic liquid, Carbon paste electrode

\section{FULL TEXT}

(C) 2020 The Authors.Published by ESG (www.electrochemsci.org). This article is an open access article distributed under the terms and conditions of the Creative Commons Attribution license (http://creativecommons.org/licenses/by/4.0/). 